\title{
Exploration and Practice of Open Experiment Project of Mechanical Manufacturing
}

\author{
WAN Hongqiang \\ School of Mechanical Engineering \\ Xi'an Technological University \\ Xian, China \\ 413162931@qq.com
}

\author{
LEI Liping \\ School of Mechanical Engineering \\ Xi'an Technological University \\ Xian, China \\ 505691193@qq.com
}

\author{
HAN Quanli \\ School of Mechanical Engineering \\ Xi'an Technological University \\ Xian, China \\ 925465354@qq.com \\ HAN Peiying \\ School of Mechanical Engineering \\ Xi'an Technological University \\ Xian, China \\ 1003575444@qq.com
}

\begin{abstract}
Mechanical basis experimental teaching demonstration center established a new experimental teaching system, in order to further improve students' ability to innovate in mechanical manufacturing. This teaching system is based on "modern design theory, mechanical manufacturing technology, electromechanical control technology, test measurement technology, information technology, and production management technology". In terms of the training of mechanical manufacturing experiment, the experimental center has carried on the exploration of comprehensive mechanical manufacturing experiment and made full use of the existing experimental platform. The experimental project is set up with the product design and multi - industrial NC machining based on CAD/CAM technology. These experimental projects are built on the platform of digital design and manufacturing systems. It includes numerical control milling experiments, cutting parameters research experiments, special processing parameters research experiments and additive manufacturing experiments. The implementation of these experiments has achieved good teaching effect. The students have the preliminary experimental exploration ability of mechanical manufacturing. The experiment of this paper provides a new idea for the cultivation of highquality talents.
\end{abstract}

Keywords-Mechanical Basic Experimental Teaching Center; Mechanical manufacturing; NC Machining; Simulation

\section{INTRODUCTION}

Experimental teaching, as an important part of the entire teaching system, is an important bridge of linking knowledge and practice, practice and innovation. Practical teaching and theoretical teaching is an important part of higher education system. It is the basic way to cultivate students 'practical ability. It is also an important way to cultivate students' professional application, analyze and solve the problem of engineering problems.

Compared with the traditional experiment, the open

Teaching Reform Research Project of Xi'an Technological University (16JGY06). experimental teaching is an experiment which is not aimed at specific students. Its experimental teaching time and way are more flexible and creative. It is an experimental teaching method which conforms to the characteristics of modern teaching ${ }^{[1-2]}$. As for how to set up an open experiment, really make it play a role in personnel training, the innovation of teaching methods and management model, and the experimental teaching system are not perfect enough ${ }^{[3-6]}$. From the requirements of mechanical engineering practice teaching system, this paper discusses the concept, content and teaching effect of open design of mechanical manufacturing ${ }^{[7]}$.

\section{MECHANICAL ENGINEERING PRACTICE TEACHING SYSTEM STRUCTURE}

In order to promote the construction of curriculum system and improve the level of training high-quality innovative talents, the center follows the rule of talent growth and experimental teaching, combines the advance with the applicability, and combines the undergraduates training with the postgraduates. On the basis of the overall optimization and improvement of the teaching links, the center has established a "one-line, three-level, four-type" experimental teaching system with modern design theory, mechanical manufacturing technology, electromechanical control technology, test and measurement technology, information technology and production management technology, as shown in Fig. 1.

"One-line": to "reinforce the foundation, pay attention to practice, open innovation" as the main line throughout the teaching system.

"Three-level": basic capacity training layer, comprehensive ability training layer and research and innovation ability training layer.

"Four-type": mechanical cognitive experiments, basic validation experiments, integrated design experiments and research innovative experiments. 


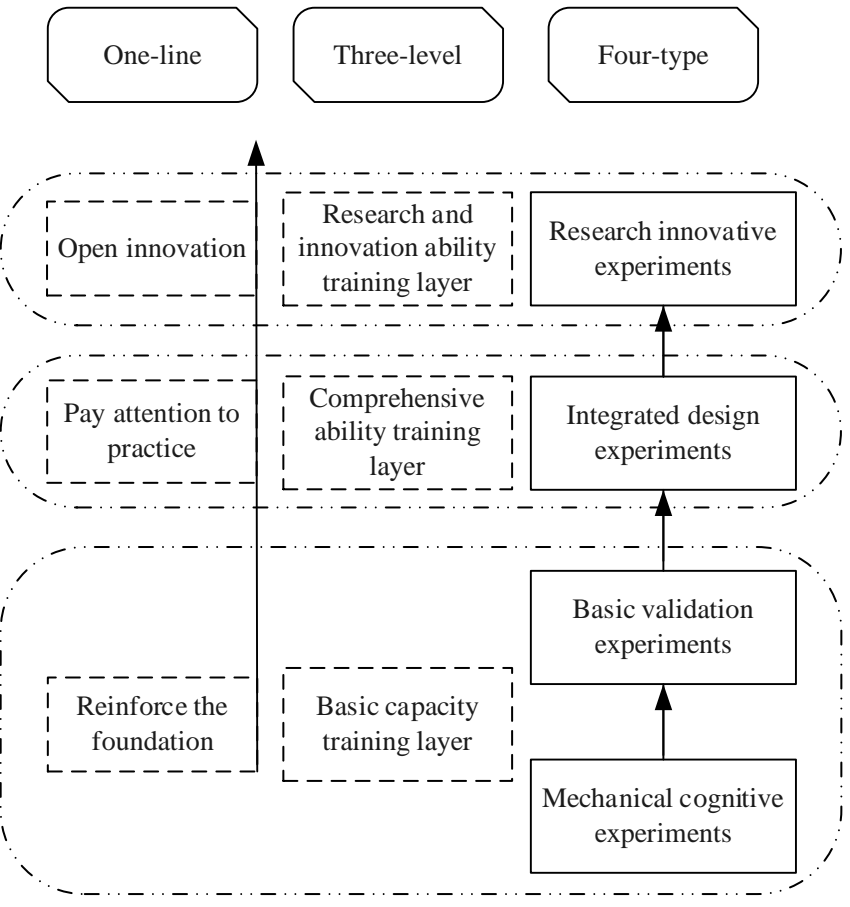

Fig. 1. Experimental teaching system figure of experimental teaching center

Centering on three elements of the "quality, ability and innovation awareness", and according to the student's cognitive rule, the center accords to the following three levels to build a practical teaching system.

- Basic capacity training level. The goal is to let students understand the basic experimental theory, data processing knowledge, experimental norms, experimental methods, learn to use of conventional experimental instruments and devices, familiar with the typical experimental principles, methods and experimental process, write experimental reports.

- Integrated capacity training level. The goal is to training students' power of using their knowledge to independently complete from the data search, the development of experimental programs and implementation, to the experimental report prepared by the whole process, emphasizing the mechanical system design, performance design and system design, improving engineering design capabilities, having preliminary ability to analyze and solve problems.

- Research and innovation ability training level. To explore a new form of Students' Innovative Practice, which is the combination of class and extracurricular, school and outside. To develop by open innovative experimental project, school-enterprise cooperation in scientific research projects, engineering practice, extracurricular innovation and other forms of practice. Through these scientific and technological activities and practice, integrate the theoretical knowledge into the research process; develop students' engineering management knowledge and academic thinking, training students' innovative and entrepreneurial ability, cooperative and communicative skills.

\section{MECHANICAL ENGINEERING OPEN EXPERIMENT TEACHING MODE AND ORGANIZATION}

Using the stronger basis of teaching and research of the mechanical engineering's first class discipline, to set up a comprehensive training project within the school and face all undergraduate students to training students' multi-disciplinary comprehensive innovation abilities. Open experimental teaching has broken the traditional closed experimental teaching mode, conformed to the modern education, teaching development requirements, and played a positive effect to cultivate students' creativity and improve the teaching quality.

Open experimental teaching organization model. The experiment is a comprehensive, designed experiment, focuses on the comprehensive, designed characteristics of the experiment, and pays attention to cultivating students' practical ability, engineering consciousness and innovative spirit, and accords to the individual circumstances of each student to implement personalized experimental teaching. Reform the experimental teaching organization model of open mechanical engineering, and all the experimental resources open to the students, so that students become the subject of the experiment, and achieve Students' Independent Experiment In the experimental teaching. Give students full autonomy in the experimental project, experimental content, laboratory equipment, experimental methods, experimental time and experimental difficulty, and other aspects, to make students choose their appropriate experimental content based on their experimental basis, professional characteristics and interests.

\section{DESIGN OF OPEN ENGINEERING EXPERIMENT FOR MECHANICAL MANUFACTURING}

Experimental content: product design and multi-type NC machining open experimental project based on CAD / CAM technology.

Students need to complete the experimental session: by product creative design and CAD parts modeling, CAM process planning and machining simulation of parts, numerical control simulation and numerical control machine operation and other practice to complete the experiment. Through this experiment students could complete all the processes involved in the NC machining process, including part modeling, trajectory generation, machining simulation, post-processing, machine operation, data transmission, tool selection, fixture design and selection, and also could fully exercise students' NC machining technology, deep theoretical teaching knowledge.

The experiment is a comprehensive training experiment on campus, it facing those students who in addition to the College of Mechanical and Electrical Engineering, Mechanical Design, Manufacture and Automation, industrial engineering, industrial design and other professional, but also facing the vehicle engineering, measurement and control technology and equipment, electronic information, materials science and engineering, materials molding and control engineering. 
Experimental basic process:

- Product creative design and CAD parts modeling. This experiment requires the experimenter go to the market, looks at the shape of hardware and small household electrical appliances, encourages students to design products on the market so that students could feel the close connection between their work and the market. Design and complete the molding, rendering, assembly of parts or products, and create engineering drawings and expressing views. The 3D modeling software includes UG, Pro/E, CATIA, SolidWorks, and so on.

- CAM process planning and machining simulation of parts. Using master CAM to check program of manual programming. As long as the NC code entered into the system, and the NC program results can be intuitive simulation by the processing track calibration, and complete manual program calibration finally.

- Numerical control simulation and numerical control machine. After completing the preparation, student could enter the program into the machine control device, install the workpiece, adjust the tool, and open the machine to complete the processing.

In addition to using NC Milling, but also using NC engraving machine, THA5656 CNC vertical machining center, FA20 Wire EDM wire cutting machine, EA22 electro sparking machine, ELB surface grinder, NC lathe center, YM-18LX shaving and grinding and polishing and other machine to complete numerical control practice (Fig. 2).

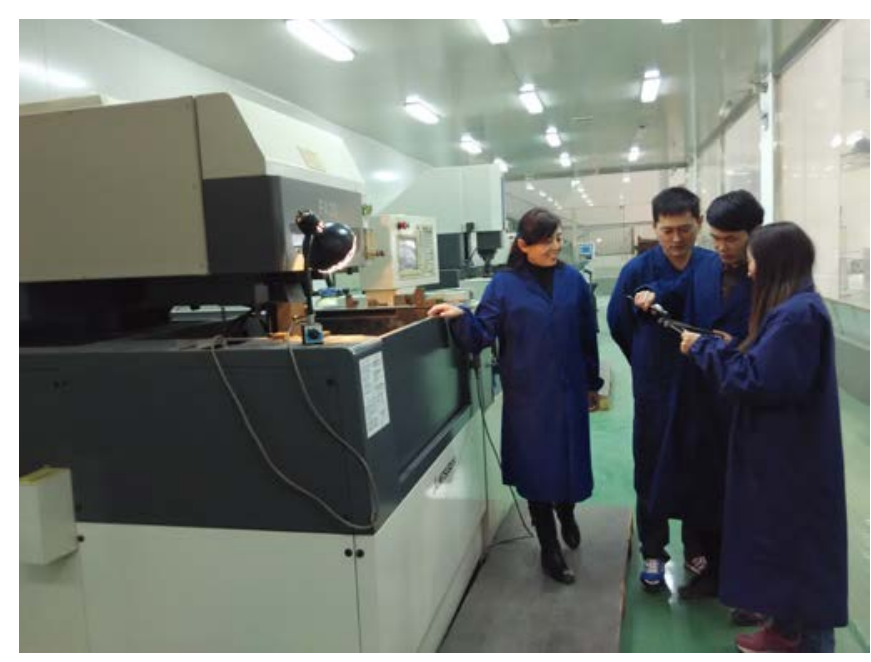

Fig. 2. Students in opening experiment

The project is implied by the manner of open experiment, the following contains multiple experiments:

- Milling experiment: 1) CAD/CAM and NC machining of revolving parts; 2) CAD modeling and NC machining based on product mold; 3) CAD/CAM and NC machining of box parts; 4) CAD/CAM software and NC engraving processing based on the carving JDPaint trademark and logo design; 5)Special processing electrode design and NC engraving processing based on the carving.
- Cutting parameters research: 1) Study on the influence of reasonable selection of milling cutter and milling amount to numerical control machining; 2) Study on the surface quality test and cutting parameters optimization of titanium alloy milling; 3) Multi-factor test on surface roughness of high strength aluminum alloy with high efficiency milling.

- The parameters research experiments of special processing: 1) Optimization of EDM process parameters of titanium alloy; 2) Optimization of EDM process parameters of carbide wire.

- The test of additive manufacturing. Design and manufacture of abnormal parts based on 3D printing technology.

\section{DESIGN OF OPEN ENGINEERING EXPERIMENT FOR MECHANICAL MANUFACTURING}

\section{A. Laboratory Introduction}

Mechanical Manufacturing Open Laboratory is an important research, teaching and innovation center for mechanical engineering, which including the large, sophisticated, valuable scientific research and machine equipment more than 20 sets. It provides trial technical services for the precision and ultra-precision machining and measurement of national local joint engineering research center, the weapons industry import test equipment maintenance center and other scientific research. It also provides technical supports for college students' extracurricular innovative activities to students make full use of existing equipment for teaching and research services. Mechanical Manufacturing Open Laboratory includes a number of laboratories, such as additive manufacturing laboratories, special processing laboratories, precision machining laboratories, CNC machining laboratories and other laboratories. The laboratory is open all day to accept students' internship and experimental services.

\section{B. Hardware Equipment}

Now the laboratory equips with ELB high-precision surface grinder, FA20M NC wire cutting machine, EA22M NC EDM machine, THA5656 NC vertical machining center, NC turning center, YM-18LX repair surface grinding and polishing machine, X5032A vertical lift milling machine, X62W universal lift milling machine, M1010 centerless grinder, MM7120A precision horizontal grinding machine grinder, M131W cylindrical grinder (universal), Y5120A gear shaper, Y3150 hobbing machine and other processing equipment, which provide a better experimental platform for the development of mechanical disciplines' and scientific research(Fig. 3).

\section{The software environment of a variety of three- \\ dimensional software as a platform}

The lab's CAD/CAM/CAE system provides a product design environmental based on processing, which enables product development from design, modeling, design simulation to machining simulation, processing, etc., achieves data integration seamlessly, optimizes product design and 
manufacturing process, and achieves the design and manufacturing process of paperless operations. Based on a variety of software-oriented process-driven technology is the key technology of virtual product development. In the environment of process-driven technology, the user's all products and accurate data models could keep correlating by the entire process of product development, and effectively implement the concurrent engineering.

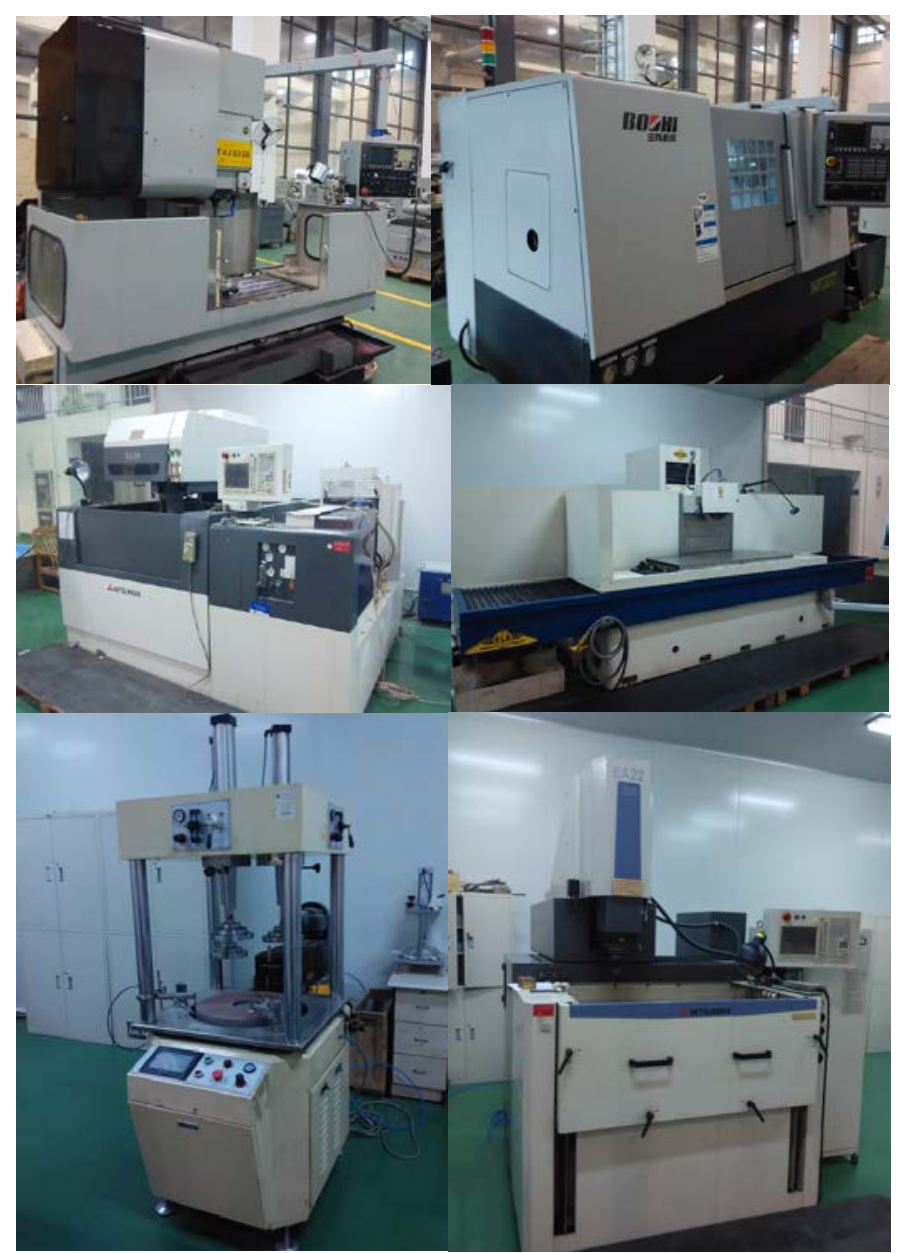

Fig. 3. Key equipment used in the experiment

\section{CONCLUSION}

Through design open integrated mechanical manufacturing experiments, could complete all the aspects of NC processing process, which Including part modeling, trajectory generation, machining simulation, post-processing, machine operation, data transmission, tool selection, fixture design and selection, and other aspects, to fully training students' mechanical manufacturing technology. From the experiment was opened, the experiment has been opened for 3 semesters continuously, nearly one hundred students benefited from it and all the students get better results. Selecting this experiment' students from multiple professions of engineering class, and has achieved good experimental teaching effect.

\section{ACKNOWLEDGMENT}

This study is funded by Teaching Reform Research Project of Xi'an Technological University (16JGY06).

\section{REFERENCES}

[1] Li Zhongxin,Feng Huihua,Cao Fengmei, “The integration and open sharing of experimental teaching resources in universities,” BEIJNG EDUCATION, vol. 2017,(01), pp. 42-45. (In Chinese)

[2] LIU Ji-xuan,CHEN Xue-feng,ZI Yan-yang,DUAN Yu-gangJ,“Open Mechanical Innovative Experimental Teaching Mode and System,” RESEARCH AND EXPLORATION IN LABORATORY, vol.2015,34(07) , pp. 184-187+203. (In Chinese)

[3] ZHAO Jing,SUN Xing-wei,LI San-san,TANG He-nan, "Research and Practice on Network Information Management," RESEARCH AND EXPLORATION IN LABORATORY, vol.2019,83(13) , pp.82-83. (In Chinese)

[4] Guo Shufang, Wu Jian, Liu Hongjun, Yin zhongwei,Xu Bin, "Mechanical principles and mechanical design experimental teaching center open experimental teaching practice”. China Modern Educational Equipment, vol.2015,34(7) , pp. 184-187+203. (In Chinese)

[5] Yan Jidong, Mou Jiping, Deng Guoping, Li Weixiong, "Practice and discussion of 'comprehensive, innovative and open experiment of mechanical design and manufacturing and automation,'”Higher Education of Sciences, vol.2007,(1), pp. 72-74. (In Chinese)

[6] PANG Yan-ying, SHI Ying-kan, QIU Dan, "Development of mechaelectronic integrated experiment device and exploration of experiment teaching”.Experimental Technology and Managemen,vol.2008,25(8), pp. 74-76+82. (In Chinese)

[7] Tao Huijin,Yin Jian,Zhou Shan,Ye Xubin, "Practice and exploration of management of openlaboratory for innovatiove talent training”. Experimental Technology and Managemen,vol.2017,34(3), pp. 25-27. (In Chinese) 